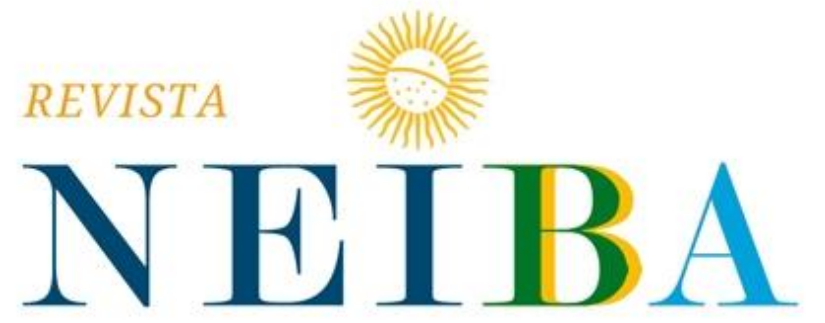

CADERNOS ARGENTINA-BRASIL

Volume 8, 2019, p. 01-20

DOI: 10.12957/neiba.2019.39503|e39503|ISSN: 2317-3459

\title{
MUSEU E COLONIALIDADE: A REPATRIAÇÃO MUSEOLÓGICA COMO INSTRUMENTO DE LUTA
}

Museum and Coloniality: The Museological Repatriation As An Instrument of Contest

\section{Mariana Pimenta Bueno ${ }^{1}$}

${ }^{1}$ Universidade do Estado do Rio de Janeiro (UERJ), Rio de Janeiro, RJ, Brasil. Bolsista da Fundação Carlos Chagas Filho de Amparo à Pesquisa do Estado do Rio de Janeiro FAPERJ. E-mail: maripimentabueno@gmail.com ORCID: https://orcid.org/0000-00018416-6208.

Recebido em: 17 jan. 2019 | Aceito em: 04 dez. 2019. 


\section{RESUMO}

Essa pesquisa exploratória parte da compreensão de museus como espaços de construção e acesso à memória, como objetivo pensar o porquê da continuidade da dominação cultural europeia sobre o continente africano, mesmo com as independências conquistadas, reproduzindo a ideia de tutela e proteção usadas durante o imperialismo europeu. O processo pela busca de um passado histórico - anterior à dominação europeia - para a formação de uma cultura nacional escrita pelo próprio povo esbarrou na ausência de artefatos que foram retirados do continente durante o imperialismo para ser expostos nos museus das metrópoles. Assim, através da análise de documentos da UNESCO, reportagens de alguns casos de pedidos de retorno de peças e a leitura de Franz Fanon, Albert Memmi, Benedict Anderson e Aníbal Quijano, a hipótese desta pesquisa é que a importância da repatriação de peças museológicas para uma cultura nacional representa uma reação à colonialidade.

Palavras-chave: Museus; repartriação; colonialidade.

\section{ABSTRACT}

Based on the understanding of museums as spaces of construction and access to memory, this exploratory research has as its objective the comprehension about the continuity of European cultural domination over African continent, even after independences have been achieved, reproducing the idea of tutelage and protection used under the European imperialism. The process of searching for a historical past before to the European domination - toward the constitution of a national culture written by themselves reaches its limits within the absence of artifacts which were removed from the continent throughout the imperialism, to be exhibited inward museums from their metropolis in museums. Therefore, through the analysis of UNESCO documents, there are reports of some cases of requestings for the restoration of the heritage and the reading of Franz Fanon, Albert Memmi, Benedict Anderson and Aníbal Quijano, the hypotesis of this research lays on the importance of museum pieces repatriation to a culture means a reaction to coloniality.

Keywords: Museum; repatriation, coloniality. 


\section{O IMPERIALISMO EUROPEU E SUAS ARMAS (IN)VISÍVEIS}

O imperialismo ${ }^{1}$ promovido pelos europeus e iniciado no século XIX colonizou povos africanos e asiáticos de diversas formas, podendo-se destacar a criação de mecanismos de alienação, que atingiu e, por vezes, eliminou a cultura local daqueles que eram colonizados. Na lógica imperialista isso era entendido como necessário, pois expressava a clara definição de quem era o subordinado e quem era o subordinante. Como exposto por Albert Memmi ${ }^{2}$ (2016), o colonizado existia porque havia também o colonizador, uma vez que a criação desta imagem era vantajosa economicamente, refletindo na estratificação do poder a hierarquia em diversos âmbitos.

O continente africano foi uma arena da disputa entre os países europeus por mercado, matérias-primas para a indústria e capital, tendo a colonização como meio na luta contra os adversários ${ }^{3}$. E foi durante essa etapa que o imperialismo europeu constituiu nos moldes de seus Estados-Nações as linhas do território africano para atenderem suas próprias demandas, desconsiderando qualquer vestígios históricos dos povos, tirando dos colonizados a possibilidade da formação de uma cultura nacional. Benedict Anderson (2008) em sua obra explicitou como esses novos Estados não apresentavam um caráter nacionalista, já que a imposição de costumes e regras europeus se fazia presente, não cedendo assim espaço para um sentimento autóctone.

Ademais, os colonizadores traçaram fenótipos almejando hierarquizar essas sociedades, ignorando as origens e funções, criando "identidades imaginadas pela mentalidade (confusamente) classificatória do Estado colonial" (Anderson, 2008, p. 229). Por essa esquematização de identidades, toda a vida na colônia era estruturada sobre esse princípio etno-racial. Dessa maneira, o colonizador ignorava qualquer diferença de origem, religião ou de trabalho, para pôr todos em "identidades" criadas por europeus, misturando diversas origens étnicas.

\footnotetext{
${ }^{1}$ O conceito imperialismo esteve subjacente em diversos autores, como Lenin, Hilferding, Hobsbawm, entre outros. No entanto, tal como exposto pelo primeiro, foi J. A. Hobson que utilizou este conceito para expor de maneira negativa as relações de exploração entre Inglaterra e Índia (Lênin, 2008). Dentre tantas, opto pela teoria de Lênin, cujo imperialismo era "desenvolvimento e continuação direta das características fundamentais do capitalismo em geral" (Lenin, 2008, p. 87), em que seria "fase monopolista do capitalismo" (op. cit., p. 87).

${ }^{2}$ Ensaísta nascido em Túnis, Tunísia. Após a independência, emigrou para França.

3 Para maiores informações, consultar a obra seminal de Eric Hobsbawm "A Era dos Impérios".
} 
Tal como observado por Frantz Fanon ${ }^{4}$ (1968) o colonialismo aniquilou o passado desses povos, desvalorizando suas raízes e histórias. Para isso, entre os diversos mecanismos (in)visíveis foram utilizados, como por exemplo o sistema educacional construído nos moldes europeus e com uma forte hierarquização. Para demonstrar o poderio britânico nas escolas de suas colônias, havia exposições de quadros de grandes escolas localizadas na metrópole para que se demonstrasse "às raças atrasadas de que elas faziam parte do Império" (Ranger, 1997, p.225).

Porém, havia também os jovens colonizados que alcançaram as universidades das metrópoles. Mesmo com a possibilidade de acessar ideias e novas literaturas, estes poderiam não reagir ao colonialismo, uma vez que estivessem na metrópole daquele poder que o colonizava, poderiam absorver visões do colonizador se tornando segundo Fanon - "intelectuais colonizados" (Fanon, 1968, p.174); mas nunca um europeu. Portanto, um homem negro africano poderia até assumir um posto de governo, mas só se absorvesse o aprendizado britânico, permanecendo preso à subordinação da tradição inventada pelos europeus para justificar essa dominação. Para que a luta pela independência fosse total era preciso desconstruir teoricamente esses intelectuais, tendo como meio a busca por histórias da pré-colonização em uma tentativa de encontrar nesse passado o constructo da cultura nacional do futuro para se (re)conhecer e criar o sentimento nacional, previamente negado pelo imperialismo. No entanto, essa busca encontrou como obstáculo a ausência de artefatos que remetessem a esse tempo.

Mesmo com a vitória pelas lutas pela independência durante o século XX, muitas peças originárias do continente africano permanecem em museus dos antigos colonizadores. Tal como o Museu Britânico que apresenta diversas galerias com peças de todo o mundo, sendo que muitas vieram como espólio de sua ocupação nos continentes africano e asiático ${ }^{5}$. Assim, deve-se questionar o porquê da continuidade dessa dominação cultural mesmo com o reconhecimento da soberania das ex-colônias, mantendo essas peças fora do seu território de origem.

\footnotetext{
${ }^{4}$ Psiquiatra francês nascido na Martinica, esteve envolvido na luta pela independência da Argélia.

${ }^{5}$ Criado em 1753, pode-se encontrar no museu cerca de 200 mil peças na galeria "África", por exemplo. Para maiores informações, acessar https://www.britishmuseum.org/.
} 
Aqui entendemos o termo colonialidade conforme a definição dada por Aníbal Quijano (2007) em que há "elementos constitutivos e específicos do padrão mundial de poder capitalista" (p. 93) ${ }^{6}$, que se difere do colonialismo ainda que ambos estejam intrinsicamente ligados. Uma dominação que sai do âmbito do controle político e econômico explícito e presencial, "transcende as particularidades do colonialismo histórico e que não desaparece com a independência ou descolonização" com um modus operandi que favorece tanto a constituição quanto a perpetuação da existência de sujeitos subalternizados nas esferas intra e interestatais" (Assis, 2014, p. 614).

\section{REPATRIAÇÃO: LUTA PELO RETORNO DA PRÓPRIA HISTÓRIA}

Anderson (2008) escreveu que muitos consideram a língua em comum um fator de condição nacional. Porém para o autor ela seria como um gerador de comunidades imaginárias, devendo-se assim considerar outros aspectos característicos de uma cultura nacional, como peças museológicas. Dessa maneira, museu compreende em seus diversos significados o de ter como função a estruturação da memória de um povo, pois sem essa haveria um risco que um povo "se extinguir" (Pinto, 2013, p. 90).

Conforme Fanon escreveu, os colonizadores acreditavam que ao sair do território seria "o retorno à barbárie, ao aviltamento, à animalização" (1968, p. 175), ou seja, defendiam os "irracionais" colonizados contra si próprios - justificativa protetora também foi usada por Quijano (2007). A cultura antes exibida era a europeia e não a de seu próprio país. Como irracionais teriam uma cultura própria? Para os europeus era sua cultura que deveria ser assimilada, o que resultou a uma alienação cultural. Fanon (1968) ainda escreveu que o intelectual colonizado deveria lutar de forma continental contra o colonizador, já que este subjugou o colonizado, ignorando origem étnica e nacionalidade. A partir da chegada do colonizador europeu houve uma padronização de todos os africanos em uma identidade só$^{7}$. Assim, a necessidade da luta pelo passado correspondia à questão de afirmação da cultura africana.

\footnotetext{
${ }^{6}$ Do original "elementos constitutivos y específicos del patrón mundial de poder capitalista." (Quijano, 2007, p. 93).

${ }^{7}$ Como dito por Fanon (1968) "O negro que jamais foi tão negro como a partir do instante em que esteve sob o domínio do branco" (p. 176)
} 
Entretanto, como citado na seção anterior, o acesso ao período pré-imperialista chocou-se com ausência de peças importantes para a cultura nacional de seu território. Os colonizadores levaram inúmeros artefatos para serem expostos em museus da Europa como forma de demonstração de poder, além de sítios arqueológicos comandados pelos mesmos. Sua usurpação e a reprodução de um poderio podem ser vistas até os dias atuais, em diversos lugares da Europa. Durante o imperialismo, apenas a verdade europeia era legítima, a que detinha o conhecimento válido e a que compreendia o sujeito como racional; enquanto o colonizado era o irracional, aquele que precisava de proteção. Em outras palavras, a Europa era a "mãe" protegendo seu "filho", os continentes africano e asiático.

Nesse ponto é necessário recorrer a exposição de Quijano (2007) sobre a percepção europeia acerca do conhecimento: a sociologia era destinada para estudar esse sujeito racional europeu, enquanto a etnografia estudava o sujeito não europeu, o exótico. Logo, pode-se compreender que os diversos sítios arqueológicos montados por expedições europeias e os artefatos levados para o continente das metrópoles era o claro exemplo dessa racionalidade investigativa, e que ao mesmo tempo assumia o papel de contador de uma história alheia escavada.

Posto isso, um questionamento emergiu: qual história sobre a África está sendo transmitida no mundo? Para Fanon (1968) a história seria "evidentemente, escrita pelos ocidentais e para os ocidentais" (p. 182), que destacariam alguns momentos do passado do continente construindo uma memória própria da visão do colonizador, reafirmando, mais uma vez, a sua versão como legítima. Dessa forma, pode-se pensar como o colonizador se colocou na posição do detentor do conhecimento ao retirar artefatos importantes - ou que não tinha um significado valoroso para aquele povo - para levar ao mundo civilizado "o exótico" que havia conquistado ${ }^{8}$. Assim, ignorando a função daquele objeto, os imperialistas europeus usurparam aquilo que consideravam como seu, abrangendo não só matérias-primas como também esculturas de templos localizados nos territórios dominados.

\footnotetext{
${ }^{8}$ Recorro aqui a ideia apresentada por Edward Said (2011) sobre a percepção europeia sobre o oriente exótico.
} 
Anderson afirmou que "a condição nacional é praticamente inseparável da consciência política" (2008, p. 191). Posto isto, entende-se que os ex-colonos assumiram um entendimento de pertencimento, tendo um mesmo objetivo para sua nação gerando vontade política para assumir sua terra. Sendo assim, quando as lutas pela independência eclodiram no último século, diversos temas foram postos para criar a condição de luta, e a questão cultural como forma de emancipação do imperialismo europeu foi uma delas. Por mais que Fanon, Memmi e outros ensaístas e líderes desses movimentos não abordassem especificamente a questão museológica, propõe-se aqui estudar como o resgate da memória e a criação de um nacionalismo cultural - que passaria pela presença de bens culturais como artefatos - contribuiria para esta criação da consciência nacional.

O debate sobre a propriedade de bens culturais vem nas últimas décadas ascendendo, tendo uma importante movimentação para repatriar artefatos museológicos, especialmente nos países africanos. Um exemplo deste momento foi o movimento de estudantes da Universidade de Cambridge na Inglaterra - não obstante o governo nigeriano ter pedido anteriormente o retorno das mesmas ${ }^{9}-$ que levou à retirada de uma estátua de bronze e ao início de uma tentativa de repatriar os objetos vindos de uma ação promovida pelos britânicos no território antes conhecido como Império do Benim - atual Nigéria - em 1897. Essa ação foi uma demonstração do poder britânico, que em uma ação punitiva sobre esse território africano por represália à morte de nove oficiais britânicos, saqueou a cidade, anexou o país ao império e exilou o rei Oba Ovonramwen ${ }^{10}$. Diante este fato, pergunta-se quais são os meandros para os pedidos de repatriação?

\section{A UNESCO COMO ARCABOUÇO INSTITUCIONAL PARA O RETORNO}

\footnotetext{
9 Segundo reportagem " Cambridge college's bronze cockerel must go back to Nigeria, students say" do jornal britânico The Guardian, estudantes votaram a favor do retorno dessas peças para a Nigéria já que no mundo atual, o movimento pela justiça global combina com o propósito da Universidade.

10 "Oba" significa rei.
} 
De acordo com a Organização das Nações Unidas para a Educação, a Ciência e a Cultura (UNESCO) $)^{11}$ o entendimento dado sobre os museus abrange não só "espaços para a transmissão cultural, o diálogo intercultural, o aprendizado, a discussão e o treinamento, também desempenham um importante papel na educação (formal, informal e continuada), na promoção da coesão social e do desenvolvimento sustentável"12. Da mesma forma foi pautada pela agência a responsabilidade de os Estados protegerem seus patrimônios culturais e naturais dentro de sua jurisdição. Nesta seção iremos trazer à luz o papel da UNESCO, através de documentos, tendo o museu como lugar de transmissão de patrimônio.

Em 1970 esta mesma organização fomentou a "Convenção relativa às medidas a serem adotadas para proibir e impedir a importação, a exportação e a transferência de propriedade ilícitas de bens culturais", que de forma ampliada falou sobre as medidas preventivas contra roubos e exportações e importações ilícitas, assim como inventários, criação de centros de conservação e museus para que os bens culturais estivessem em seus territórios de origem protegidos e preservados. Entendeu-se também que, além de um intercâmbio cultural de bens entre as nações que fomentam o conhecimento científico, cultura e de educação, a importância desses bens em seus países de origem são vistos como elementos imprescindíveis de uma sociedade, pois "bens culturais constituem um dos elementos básicos da civilização e da cultura dos povos, e que seu verdadeiro valor só pode ser apreciado quando se conhecem, com maior precisão, sua origem, sua história e seu meio ambiente" (UNESCO, 1970).

Na Convenção, o conceito de bens culturais é definido no artigo primeiro como "quaisquer bens que, por motivos religiosos ou profanos, tenham sido expressamente designados por cada Estado como de importância para a arqueologia, a pré-história, a história, a literatura, a arte ou a ciência" (UNESCO, 1970). Dentre esses bens enquadram- se peças referentes à zoologia, manuscritos, objetos etnológicos,

\footnotetext{
${ }^{11}$ A UNESCO é a agência criada após da Segunda Guerra Mundial com o objetivo de garantir a paz através da cooperação intelectual entre os Estados. Para maiores informações, acesse o sítio https://nacoesunidas.org/agencia/unesco/.

12 Recomendação referente à Proteção e Promoção dos Museus e Coleções, sua Diversidade e seu Papel na Sociedade aprovada em novembro de 2015.
} 
arqueológicos, gravura, antiguidades de mais de 100 anos, dentre outros. Ou seja, aqueles relacionados à história de um povo.

Nos artigos também é exposta a importância de os Estados terem legislações para a proteção do patrimônio, promoverem o desenvolvimento ou a criação de instituições científicas e técnicas, tais como os museus e bibliotecas (UNESCO, 1970), além de normas para bloquear o tráfico de bens culturais. Ademais, no artigo 5o explicita-se a necessidade de equipes especializadas para tarefas como a supervisão das escavações em sítios arqueológicos, a promoção da educação sobre a importância desses bens, a formulação de regulações para proteger e publicidade caso haja desaparecimento de algum objeto.

Seguindo com o documento em questão, o texto do artigo 7 prevê a necessidade de museus estrangeiros estabelecerem uma ligação para informar a entrada de bens de um outro país, a proibição de importar "bens culturais roubados de um museu, de um monumento público civil ou religioso, ou de uma instituição similar situados no território de outro Estado-Parte na presente Convenção" (UNESCO, 1970) mediante comprovação por inventário, assim como

tomar as medidas apropriadas, mediante solicitação do Estado de origem Parte na Convenção, para recuperar e restituir quaisquer bens culturais roubados e importados após a entrada em vigor da presente Convenção para ambos os Estados interessado, desde que o Estado solicitante pague justa compensação a qualquer comprador de boa fé ou a qualquer pessoa que detenha a propriedade legal daqueles bens. (UNESCO, 1970).

No entanto, pode-se problematizar esse artigo, posto que o pedido de um inventariado em um período que houve a dominação imperialista torna-se difícil, uma vez que a cultura sobrevivente muitas vezes é a oral, assim como o desconhecimento de todas as peças retiradas ao longo desse período. Além do mais, o viés financeiro também torna-se um elemento problemático, uma vez que muitos países africanos têm pouca condição de compensar financeiramente um proprietário de algum bem retirado e vendido.

Já o artigo 9o e 10 abordam a questão da necessidade de sanções dentro dos Estados-Partes e de cooperação internacional para a proteção dos bens culturais 
respectivamente. Já para 10ำ artigo os Estados-Partes têm como obrigação de "restituir, através da educação, informação e vigilância, a circulação de qualquer bem cultural removido ilegalmente de qualquer Estado-Parte" e ter sanções aos que praticam o crime de roubo de bens culturais, o primeiro artigo abordou que

\begin{abstract}
Qualquer Estado-Parte na presente Convenção, cujo patrimônio cultural esteja ameaçado ou em consequência da pilhagem de materiais arqueológicos ou etnológicos, poderá apelar para os outros Estados-Partes que estejam envolvidos. Os Estados-Partes na presente Convenção se comprometem, em tais circunstâncias, a participar de uma ação internacional concertada para determinar e aplicar as medidas concretas necessárias, inclusive o controle das exportações e importações do comércio internacional dos bens culturais em questão. (UNESCO, 1970).
\end{abstract}

O artigo 11을 apresenta o entendimento sobre a ilicitude daqueles bens que foram levados de seus países de origem de forma forçada durante uma ocupação de um território por uma potência estrangeira. E no artigo 12ㅇ expõe-se que os Estados "respeitarão o patrimônio cultural dos territórios por cujas relações intencionais sejam responsáveis" (UNESCO, 1970). Além disso, no artigo 15 há uma importante norma sobre acordos bilaterais para que possamos entender o movimento pelo retorno de peças, refletindo a possibilidade de Estados terem um movimento próprio de acordo, para romperem com os resquícios dos anos de colonialismo em determinadas regiões:

Nada na presente Convenção impedirá os Estados-Partes na mesma de concluir acordos especiais entre si, ou de continuarem a implementação de acordos já concluídos, sobre a restituição de bens culturais removidos, por qualquer razão, de seu território de origem, antes da entrada em vigor da presente Convenção para os Estados em questão. (UNESCO, 1970).

Já no artigo 13, os Estados-Partes devem agir de acordo com as legislações internas para

a) impedir, por todos os meios apropriados, as transferências de propriedade de bens culturais que tendam a favorecer a importação ou exportação ilícitas de tais bens;

b) assegurar que seus serviços competentes cooperem para facilitar a restituição, o mais breve possível, a seu proprietário de direito, de bens culturais ilicitamente exportados;

c) admitir ações reivindicatórias de bens culturais roubados ou perdidos movidos por seus proprietários de direito ou em seu nome;

d) reconhecer o direito imprescritível de cada Estado parte na presente Convenção de classificar e declarar inalienáveis certos bens culturais, os 
quais, ipso facto, não poderão ser exportados, e facilitar a recuperação de tais bens pelo Estado interessado, no caso de haverem sido exportados.

Outrossim, a Convenção aborda o papel da UNESCO para a assegurar que não haja movimentos ilícitos dos bens culturais. Nos artigos 160 e 17으 o texto traz que os deveres e direitos Estados-Partes para com a agência das Nações Unidas, como a emissão de relatórios para demonstrar o que tem sido feito pelos mesmos para a aplicação da Convenção, bem como a possibilidade de solicitarem assistência técnica da agência. Esta também se assegura em poder pesquisar sobre as ilicitudes de circulação de bens e propor visitas aos Estados para implementarem a Convenção no território.

Diante as informações apresentadas, cabe retornar ao artigo 2 da Convenção para compreender que esse movimento ilícito de bens culturais é considerado como "uma das causas principais do empobrecimento do patrimônio cultural dos países de origem" (UNESCO, 1970) e que a colaboração internacional seria um dos instrumentos mais eficazes para proteger bens culturais. Entretanto, há certa problemática nesse ponto quando se consulta o histórico de não retorno de muitas peças aos seus territórios de origem, assim como a desconfiança dos efeitos do longo tempo de colonialismo nos termos da colaboração internacional, uma vez que ainda têm-se relações centroperiferia no sistema internacional. Sendo assim é importante que os acordos sejam explícitos e bem especificados para que não haja a repetição das relações de dominação passadas entre os Estados-Partes.

Portanto, a Convenção apresenta-se como um instrumento para o entendimento da importância de bens culturais para a sociedade, prevendo que através da educação promovida pelo Estado desenvolver-se-ia em sua população o sentimento de valorização daqueles bens culturais, entendendo que a exportação ou tráfego ilícito ferem seu patrimônio cultural. Os artigos aqui trazidos foram importantes para compreender como é fundamental que o conhecimento das origens de um povo seja reconhecido por todos, além de igualar todos os Estados no sistema internacional na questão do acesso à cultura, conhecimento e soberania. 
Porém, a Convenção ainda esbarra em um dos argumentos imperialistas, em que o colonizado era "irracional" e precisaria de cuidados, conforme já citado. Ela estipula que o Estado deve zelar pelo patrimônio "contra perigos de roubo, escavação clandestina e exportação ilícita" (UNESCO, 1970, Preâmbulo). Muitos países subdesenvolvidos são excolônias e sofrem mesmo após a independência no que diz respeito às condições econômicas. Este fato torna-se justificativa comumente utilizada por grupos para defender a continuidade das peças em museus e em institutos de países centrais, que por vezes são as ex-metrópoles, afirmando terem melhores condições de cuidar de peças museológicas do que os seus países de origem. Portanto, encontra-se mais um exemplo da reprodução do discurso de protetorado por parte das metrópoles durante a colonização, tal como descrito por Memmi (2016).

Além da Convenção de 1970, a UNESCO também criou o "Comitê Intergovernamental para Fomentar o Retorno dos Bens Culturais a seus Países de Origem ou sua Restituição em Caso de Apropriação llícita", em 1978, com a presença dos Estados-Partes da UNESCO. Conforme traz o "Estatuto do Comitê Intergovernamental para Fomentar o Retorno dos Bens Culturais a seus Países de Origem ou sua Restituição em Caso de Apropriação llícita” do ano de 2005, definiu-se com base no documento de 1978 - o que se considerava como bens culturais e, como descrito no Artigo 3o, a possibilidade

de uma petição relativa ou ao retorno [...] de todo bem cultural que tenha uma significação fundamental desde o ponto de vista dos valores espirituais e o patrimônio cultural do povo de um Estado Membro [...] e que tenha sido perdido como consequência de uma ocupação colonial ou estrangeira ou de resultados de uma apropriação ilícita ${ }^{13}$. (UNESCO, 2005)

Dentre as atribuições do Comitê, destaca-se a tentativa em auxiliar, através de acordos e cooperações bilaterais ou multilaterais, o imbróglio da restituição de bens culturais, tal como descrito no artigo 4ㅇ․ Ademais pode também mediar através de

\footnotetext{
${ }^{13}$ Do original "una petición relativa a la restitución o al retorno por parte de un Estado Miembro [...] de todo bien cultural que tenga una significación fundamental desde el punto de vista de los valores espirituales y el patrimonio cultural del pueblo de un Estado Miembro [...], y que haya sido perdido como consecuencia de una ocupación colonial o extranjera o de resultas de una apropiación ilícita." (UNESCO, 1978).
} 
formulações de propostas para ajudar os Estados-Partes nesse processo de retorno dos bens culturais.

Na 21a Conferência Geral, realizada em 1980 em Belgrado, o debate acerca do retorno de bens culturais começou tendo a 22a Conferência de 1983 reforçando alguns parâmetros necessários para o retorno desses bens como negociações bilaterais e cooperação técnica para preservar os patrimônios. Dentre as recomendações, houve a citação de casos de sucesso de retorno, como o de tábuas cuneiformes ao Museu Nacional de Bagdá pelo Museu Semítico da Universidade de Harvard e pelo Instituto Oriental de Chicago, assim como a luta da Grécia com o Reino Unido pela devolução dos mármores do Parthenon através de acordo bilateral, as preocupações sobre a expatriação do patrimônio cultural árabe e a importância para os países periféricos da repatriação de seus bens culturais como mecanismo para o fortalecimento da identidade cultural.

Ademais, o movimento sobre a questão da repatriação chegou à Assembleia Geral das Nações Unidas com a resolução de "Restituição de trabalhos artísticos a países vítimas de expropriação" que respaldaram a questão sobre os bens culturais: a 3187 (XXVIII) de 1973 e a 3391 (XXX) de 1975. Ambas reafirmaram, através da Declaração sobre a Concessão da Independência aos Países e Povos Coloniais e da Convenção de 1970, que a restituição de peças museológicas, manuscritos, entre outros, promoveriam a cultura nacional e que os países que tivessem acesso a essas peças teriam a obrigação de procurar uma cooperação com o país ex-colônia. Como exposto por Folarin Shyllon (2000), com as lutas pela independência acontecendo, a resolução 3187 teve 20 estados, todos africanos, promovendo-a.

No século XXI, a UNESCO apresentou alguns casos de sucesso de repatriação ${ }^{14}$, como o caso do retorno da estátua Venus de Cyrène, em 2007 à Líbia. A estátua foi levada, em 1913, para a Itália enquanto o território líbio estava sob seu domínio ${ }^{15}$. Em

\footnotetext{
14 Para saber mais casos de repatriação, acesse o website da UNESCO em http://www.unesco.org/new/en/culture/themes/restitution-of-cultural-property/successful-restitutions-in-theworld/.

${ }^{15}$ A dominação italiana sob a Líbia data desde a assinatura do Tratado de Lausana, em 1912, quando a Turquia cedeu seus direitos sob o território líbio à Italia. Durante a Primeira Guerra Mundial, os líbios retomaram o controle de quase toda sua extensão. Porém em 1939, foi reconquistada e incorporada à Itália. Somente após a Segunda Guerra Mundial, em 1951 foi declarada independência pelo Rei Idris I.
} 
1989, o país africano requisitou a repatriação da estátua e em 1998 ocorreu uma Joint Communiqué com a ideia de que dever-se-ia devolver todas as peças retiradas do território enquanto havia o domínio italiano. Entretanto, o imbróglio durou até o ano 2000, quando os dois países fizeram um acordo que acertava a repatriação da estátua. Mesmo com esse acordo, uma organização não governamental chamada Italia Nostra tentou anular o decreto de 2002, que autorizava a ida da peça, com o argumento que a estátua fazia parte de uma herança cultural, já que a Líbia fora colônia italiana e seus bens pertenciam então a metrópole; no fim a organização perdeu a ação. Depois de mais sete anos do fechamento do acordo, o Tribunal Administrativo Regional ${ }^{16}$ italiano confirmou a validade decisória anterior e, em 2008, a estátua Vênus de Cyrène finalmente retornou ao seu país de origem ${ }^{17}$.

Esse caso é um exemplo da problemática que envolve o retorno de peças museológicas para o país de origem. Considerando os já citados artigos da Convenção de 1970 da UNESCO, das resoluções do Comitê Intergovenamental da mesma agência, as recomendações da Assembleia Geral das Nações Unidas sobre o assunto, o retorno pode ser interpretado como parte de uma reparação aos países dominados com a da devolução de artefatos retirados durante o período colonizador. Entretanto, a identidade criada pelos colonizadores de protetores desses povos "irracionais" permaneceu ao longo dos anos, com a ideia de que os museus da Europa, no caso, têm o direito sob essas peças, ignorando os anos de dominação pela metrópole.

\section{"HÁ UMA GOTA DE SANGUE EM CADA MUSEU"18}

Anderson escreveu que "os museus e a imaginação museológica são profundamente políticos" (2008, p. 246). Durante a ocupação europeia houve um investimento em arqueologia monumental que representava a necessidade de legitimação como protetor daqueles povos. O autor ainda pontuou que a rivalidade entre as nações europeias incluía até mesmo o âmbito cultural. Partindo dessa

\footnotetext{
${ }^{16}$ Em italiano Tribunale Amministrativo Regionale (TAR).

${ }^{17}$ Para saber mais detalhes desse processo, consulte https://plone.unige.ch/art-adr/cases-affaires/venus-of-cyrene2013-italy-and-libya.

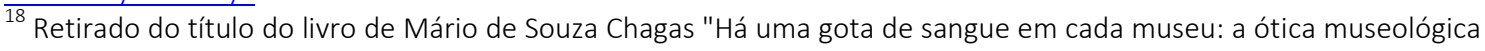
de Mario de Andrade", publicado em 2006 pela Editora Argos.
} 
premissa, podemos entender por que a repatriação de peças museológicas - além da criação de museus - são importantes para países antes colonizados. Tal como foi escrito por Anderson, "decerto não surpreende muito que os estados pósindependência, que mostravam nítidas continuidades com os antecessores coloniais, tenham herdado essa forma de museificação política" (2008, p. 251), criando elementos ligados ao Estado.

Dessa maneira, expor sua cultura é exaltar, conhecer e construir uma memória de seu país. Ter as peças museológicas que contam seu passado para a construção do futuro é algo comum em todos os países, não sendo diferente no objetivo daqueles que foram dominados durante o século XIX e parte do XX. Para requisitar as peças, Shyllon (2000) apresentou quatro mecanismos classificados por ele como "Velhas Opções": como a Convenção de 1970 já citada, o Comitê Internacional da UNESCO, acordos bilaterais (como o da Itália com a Líbia) ou litígio em cortes internacionais. Entretanto, alguns países africanos não podem pagar os custos de uma corte internacional ou provar a ida do artefato de forma ilícita. Mesmo assim, a importância da UNESCO é visível por garantir assistência aos seus Estados-Membros.

Shyllon (2000) expôs uma "nova opção"19: a arbitragem. Esta nova forma está prevista pelo artigo 8ㅇ da Convention on Stolen or Illegally Exported Cultural Objects do The International Institute for the Unification of Private Law (UNIDROIT) de 1995, uma organização intergovernamental que busca alinhar o direito privado entre os Estados. Este prevê que "as partes podem concordar em submeter o litígio a qualquer tribunal ou outra autoridade competente ou a arbitragem." (Shyllon, 2000, p.225) 20

Por que uma repatriação é um processo demorado? Muitas requisições esbarram no argumento de peças estarem em museus europeus significa que fazem parte da história daquele país que ocupou, ignorando o fato de terem sido retiradas de forma arbitrária. Além disso, muitos não possuem o inventário daquilo que foi levado ou, até mesmo, não têm a chance econômica de requisitar. Até mesmo a Grécia, um país

\footnotetext{
19 Segundo Shyllon (200) esta possibilidade surgiu pela primeira vez em 1983 na reunião do Comitê Intergovernamental quando o presidente das três primeiras sessões, Salah Stetie, expõs a possibilidade do Comitê "had emphasised that according to procedures defined by the Committee it could only intervene when bilateral negotiations between nations had failed" (p.226).

20 Do original "It provides that "[t]he parties may agree to submit the dispute to any court or other competent authority or to arbitration." (Shyllon, 2000, p.225).
} 
localizado no continente europeu, está envolvido em um imbróglio com o Museu Britânico por causa dos mármores do Parthenon uma vez que o retorno permitiria que as peças ficassem reunidas.

Memmi escreveu que "o colonizador nega ao colonizado o mais precioso direito reconhecido à maior parte dos homens: a liberdade" (2016, p. 123). Logo, o que ainda acontece é uma constante negação à liberdade e aos bens culturais; uma negação que restringe o acesso à cultura e à educação, perpetuando uma dominação e um retrato do europeu protetor e do africano passível de sua proteção. Todavia, o movimento se afasta do conceito anti-colonialista e se aproxima do decolonialista, pois conforme a definição de Quijano (2007), colonialismo e colonialidade são conceitos distintos ainda que o segundo esteja ligado ao primeiro. O colonialismo está ligado ao capitalismo e à modernidade, "uma relação política e econômica, na qual a soberania de um povo reside no poder de outro povo ou nação, o que constitui a tal nação em um império" (Quijano, 2007, p.131) 21. Já colonialidade é definida como

um padrão de poder que emergiu como resultado do colonialismo moderno, mas que ao invés de estar limitado a uma relação formal de poder entre dois povos ou nações, melhor se refere a forma como o trabalho, o conhecimento, a autoridade e as relações intersubjetivas se articulam entre si, através do mercado capitalista mundial e da ideia de raça. (Quijano, 2007, p.131) 22

Assim, essa colonialidade permanece quando acaba o colonialismo, fato que pode ser observado na relação entre Europa e África na questão cultural. O colonizador europeu determinou fenótipos para justificar seu domínio, além de criar a colonialidade nas relações culturais. Como já citado, o colonizador impôs sua hegemonia cultural, ignorando e destruindo os demais conhecimentos, criando uma relação entre vencidos e vencedores, com uma só cultura legítima: a do vencedor.

\footnotetext{
${ }^{21}$ Do original "en la cual la soberanía de un pueblo reside en el poder de otro pueblo o nación, lo que constituye a tal nación en un imperio.".

${ }^{22}$ No original "un patrón de poder que emergió como resultado del colonialismo moderno, pero que en vez de estar limitado a una relación formal de poder entre dos pueblos o naciones, más bien se refiere a la forma como el trabajo, el conocimiento, la autoridad y las relaciones intersubjetivas se articulan entre sí, a través del mercado capitalista mundial y de la idea de raza".
} 
Destarte, considerando as leituras apresentadas neste trabalho juntamente com os recentes movimentos observados tanto na Europa quanto na África através das reportagens trazidas, a hipótese da importância da repatriação de peças museológicas para uma cultura nacional como uma reação à colonialidade e afirmação pelo rompimento dos laços de submissão ainda presentes se confirma, a princípio. Isso porque observam-se hesitações dos museus na Europa no debate sobre o tema, com alguns grupos que consideram que as peças presentes em seus acervos meuseológicos europeus também fazem parte de uma herança cultural do período em que foram metrópoles, ignorando o contexto da saída desses bens dos territórios colonizados como por exemplo a dada pela organização não-governamental Italia Nostra durante o processo de devolução de Vênus de Cyrène à Líbia abordada na seção anterior - quanto pelo aspecto econômico de movimento turístico na Europa.

Ademais, a atenção dada pela UNESCO sobre esse assunto gera um respaldo internacional na luta pelo retorno. Dessa maneira, a repatriação de peças museológicas, além da criação de museus, instituições e de mecanismos de proteção ao patrimônio, criam um ambiente propício para a identificação do sujeito com a cultura nacional, revisitando e criando uma memória de suas origens, importantes para a quebra das correntes que encaminharia à decolonização cultural e ao reconhecimento soberano de um povo em diversos aspectos. No entanto, este permanece sendo um assunto delicado, com diversas pressões financeiras por conta do turismo cultural gerado pelos museus, o que remete às palavras de Fanon: "Sabe-se hoje que na primeira fase da luta nacional, o colonialismo procura esvaziar a reivindicação nacional recorrendo ao economicismo" (Fanon, 1968, p.172).

Portanto, essa pesquisa teve em seu caráter exploratório o objetivo de iniciar e entender quais são as formas e as dificuldades para a repatriação de peças museológicas para seus território de origem, considerando os processos de luta pelas independências e as consequências do imperialismo na subjetividade de seus povos. $E$, por isso, não se apresenta aqui uma resposta definitiva sobre a questão, uma vez que 
mais discussões deverão surgir com novos casos como o dos governos da França e Burkina $\mathrm{Faso}^{23}$.

\section{REFERÊNCIAS BIBLIOGRÁFICAS}

Anderson, B. R. (2008). Comunidades Imaginadas: reflexões sobre a origem e a difusão do nacionalismo. São Paulo: Companhia das Letras.

Assis, W. F. T. (2014). Do colonialismo à colonialidade: expropriação territorial na periferia do capitalismo. CADERNO CRH, Salvador, v. 27, n. 72, p. 613-627, Set./Dez. Disponível em: < http://www.scielo.br/pdf/ccrh/v27n72/11.pdf >. Acesso em: 10 dez. 2018.

Chechi, A.; Bandle, A. L.; Renold, M. (2012). Case Venus of Cyrene - Italy and Libya. ArtLaw Centre, University of Geneva. Disponível em: <https://plone.unige.ch/artadr/cases-affaires/venus-of-cyrene-2013-italy-and-libya> Acesso em 03 jan. 2018

Fanon, F. (1968). Os Condenados da Terra. Rio de Janeiro: Civilização Brasileira.

Lenin, V. I. (2008). O imperialismo: Fase superior do capitalismo. São Paulo: Centauro.

Memmi, A. (2016). Retrato do Colonizado: precedido do Retrato do colonizador. Rio de Janeiro: Ed. Civilização Brasileira.

Pinto, S. L. A. (2013). Museu e arquivo como lugares de memória. Museologia \& Interdisciplinariedade. Vol.I1, no3, maio/junho.

Quijano, A. (2007). "Colonialidad del poder y clasificación social". In Castro-Gómez, Santiago, and Ramón Grosfoguel, (eds.) El giro decolonial: reflexiones para una diversidad epistémica más allá del capitalismo global. Siglo del Hombre editores.

Ranger, T. (1997). "A invenção da Tradição na África Colonial" in HOBSBWAM, Eric; RANGER, Terence (Ed.); A invenção das Tradições. São Paulo: Editora Paz e Terra.

Said, E. (2011). Cultura e imperialismo. São Paulo: Companhia de Bolso.

Shyllon, F. (2000). The recovery of cultural objects by African states through the UNESCO and UNIDROIT conventions and the role of arbitration. Unif. L. Rev. ns, v. 5.

\footnotetext{
${ }^{23}$ Em 2017, ao visitar Universidade de Ouagadougou, em Burkina Faso, o presidente francês, Emmanuel Macron, afirmou em seu discurso a projeção do retorno de peças que foram roubadas quando era colônia do país europeu, mudando inclusive a lei de "inalienabilidade" do patrimônio para que essas peças saíssem e retornassem para seu território de origem (The Guardian, 2018).
} 


\section{Fontes online}

"Bronzes to Benin, gold to Ghana ... museums under fire on looted art". Ruth Maclen, The Guardian, 02 de dezembro de 2018. Disponível em: < https://www.theguardian.com/culture/2018/dec/02/british-museums-pressure-giveback--looted-african-art-treasures>. Acesso em 10 dez. 2018.

"Cambridge college's bronze cockerel must go back to Nigeria, students say". The Guardian, 21 de fevereiro de 2016. Disponível em: <https://www.theguardian.com/education/2016/feb/21/cambridge-colleges-bronzecockerel-must-go-back-to-nigeria-students-say> Acesso em 02 de jan. 2018.

"France urged to change heritage law and return looted art to Africa". Ruth Maclen, The Guardian, 21 de novembro de 2018. Disponível em: < https://www.theguardian.com/world/2018/nov/21/france-urged-to-return-lootedafrican-art-treasures-macron>. Acesso em 10 dez. 2018.

"França quer devolver obras de arte e objetos africanos roubados no período colonial", O Globo, 21 de novembro de 2018. Disponível em: https://oglobo.globo.com/cultura/franca-quer-devolver-obras-de-arte-objetosafricanos-roubados-no-periodo-colonial-23248469. Acesso em 22 nov. 2018.

ONU. Resolução 3187 sobre Restituição de trabalhos de arte para países vítimas de expropriação. Assembleia Geral da Nações Unidas, 1973. Disponível em: <http://www.unesco.org/culture/laws/pdf/UNGA_resolution3187.pdf > Acesso em 03 jan. 2018

ONU. Resolução 3391 sobre Restituição de trabalhos de arte para países vítimas de expropriação. Assembleia Geral da Nações Unidas, 1975. Disponível em: <http://www.unesco.org/culture/laws/pdf/UNGA_resolution3391.pdf > Acesso em 03 jan. 2018

"Spoils of war". The Guardian, 11 de setembro de 2003. Disponível em: <https://www.theguardian.com/culture/2003/sep/11/2> Acesso em 02 jan. 2018.

"The art world's shame: why Britain must give its colonial booty back". The Guardian, 4 de novembro de 2014.2 Disponível em: $<$ https://www.theguardian.com/artanddesign/jonathanjonesblog/2014/nov/04/artworlds-shame-parthenon-elgin-marbles-british-museums> Acesso em 28 dez. 2017.

UNESCO. Convenção Relativa às medidas a serem adotadas para proibir e impedir a importação, a exportação e a transferência de propriedade ilícitas de bens culturais. UNESCO, $1970 . \quad$ Disponível em: <http://unesdoc.unesco.org/images/0016/001606/160638por.pdf> Acesso em 03 de jan. 2018 
UNESCO. Estatutos del Comité Intergubernamental para Fomentar el Retorno de los Bienes Culturales a sus Países de Origen o su Restitución en Caso de Apropiación llícita. Paris, 2005. Disponível em

<https://unesdoc.unesco.org/ark:/48223/pf0000145960_spa> Acesso em 10 dez. 2018.

UNESCO. Informe do Comitê Intergovernamental para fomentar o retorno dos bens culturais a seus países de origem ou sua restituição em caso de apropriação ilícita. Conferência Geral 21a Reunião. Belgrado, 1980. Disponível em <http://unesdoc.unesco.org/images/0004/000419/041941sb.pdf> Acesso em 03 jan. 2018

UNESCO. Informe do Comitê Intergovernamental para fomentar o retorno dos bens culturais a seus países de origem ou sua restituição em caso de apropriação ilícita. Conferência Geral 22a Reunião. Paris, 1983. Disponível em <http://unesdoc.unesco.org/images/0005/000576/057604sb.pdf> Acesso em 03 jan. 2018

UNESCO. Recent examples of successful operations of cultural property restitutions in the world. Disponível em:

$<$ http://www.unesco.org/new/en/culture/themes/restitution-of-culturalproperty/successful-restitutions-in-the-world/ > Acesso em 28 dez. de 2017.

"Western museums try to forge deal with west Africa to return the Benin bronzes", The Guardian, 12 de agosto de 2017. Disponível em:

<https://www.theguardian.com/world/2017/aug/12/cambridge-benin-bronzes-loandeal> Acessado em 02 de jan. 2018. 